\title{
Number and Characteristics of US Adults Meeting Prediabetes Criteria for Diabetes Prevention Programs: NHANES 2007-2016
}

\author{
Alexandra K. Lee, PhD, MSPH, Bethany Warren, PhD, Caroline Liu, MHS, Kathryn Foti, MPH, and \\ Elizabeth Selvin, $\mathrm{PhD}, \mathrm{MPH}$
}

Department of Epidemiology and the Welch Center for Prevention, Epidemiology and Clinical Research , Johns Hopkins Bloomberg School of Public Health, Baltimore, MD, USA.

J Gen Intern Med 34(8):1400-2

DOI: $10.1007 / \mathrm{s} 11606-019-04915-\mathrm{w}$

(c) Society of General Internal Medicine 2019

\section{INTRODUCTION}

Type 2 diabetes is a major public health challenge but can be prevented. The landmark Diabetes Prevention Program (DPP) Trial demonstrated a 58\% reduction in 3-year diabetes incidence with an intensive lifestyle intervention in high-risk persons with prediabetes. ${ }^{1}$ There is substantial interest in translating this program to community settings. In 2010, the Centers for Disease Control and Prevention created a partnership called the National Diabetes Prevention Program (National DPP) and developed a set of guidance documents and steps for national certification of local lifestyle change programs. $^{2}$ In 2018, the Centers for Medicare and Medicaid Services began providing insurance coverage for Medicare beneficiaries meeting Medicare DPP criteria to attend recognized DPPs. ${ }^{3}$ As is typical for research translation, community-based programs that are part of the National DPP use less restrictive eligibility criteria than the original DPP Trial. The Medicare DPP model was certified based on expected Medicare savings. ${ }^{4}$ Differences in eligibility criteria may influence the effectiveness of the intervention and the potential influence on the diabetes epidemic. Currently, it is unknown how many adults in the USA are eligible for these programs. By each set of criteria, we sought to quantify (1) the proportion and number of US adults who would be eligible and (2) the differences in characteristics of adults identified.

\section{METHODS}

We conducted a cross-sectional descriptive analysis of adults aged 20 years or older who participated in the 2007-2016 National Health and Nutrition Examination Survey (NHANES) $(n=8792)$. We determined the proportion of the non-diabetic US population eligible for each program and compared clinical characteristics. Analyses were conducted in 2018, accounted for the complex survey design, and were weighted to the 2016 US adult population. National DPP eligibility criteria

Published online March 11, 2019 are age $\geq 18$ years, $\mathrm{BMI} \geq 25 \mathrm{~kg} / \mathrm{m}^{2}$ (Asian $\geq 23 \mathrm{~kg} / \mathrm{m}^{2}$ ), and any one of the following: HbA1c 5.7-6.4\%, fasting glucose 100 $125 \mathrm{mg} / \mathrm{dL}, 2-\mathrm{h}$ glucose 140-199 mg/dL, history of gestational diabetes, or CDC Prediabetes Risk Score $\geq 9 .^{3}$ Medicare DPP eligibility criteria are age $\geq 65$ years, BMI $\geq 25 \mathrm{~kg} / \mathrm{m}^{2}$ (Asian $\geq 23 \mathrm{~kg} / \mathrm{m}^{2}$ ), and any one of the following: HbAlc $5.7-6.4 \%$, fasting glucose 110-125 mg/dL, or 2-h glucose 140-199 mg/ $\mathrm{dL}^{2}$ DPP Trial eligibility criteria are age $\geq 25$ years, BMI $\geq 24 \mathrm{~kg} / \mathrm{m}^{2}$ (Asian $\geq 22 \mathrm{~kg} / \mathrm{m}^{2}$ ), fasting glucose 95-125 mg/ dL, and 2-h glucose 140-199 mg/dL. ${ }^{1}$

\section{RESULTS}

Overall, 101.2 million US adults $(47.7 \%)$ were eligible for National DPP in 2016, corresponding to $43.5 \%$ of adults aged $20-64$ and $69.4 \%$ of adults aged $\geq 65$ years (Fig. 1). Among adults $\geq 65$ years, $41.9 \%$ (15.3 million) were eligible for Medicare DPP. In contrast, $11.0 \%$ of adults aged 20-64 (19.1 million) and $30.2 \%$ of older adults (11.1 million) met eligibility criteria for the original DPP Trial.

Adults eligible for National DPP had more favorable risk factor profiles than those who would be eligible for the DPP Trial, as assessed by body mass index, lipids, blood pressure,

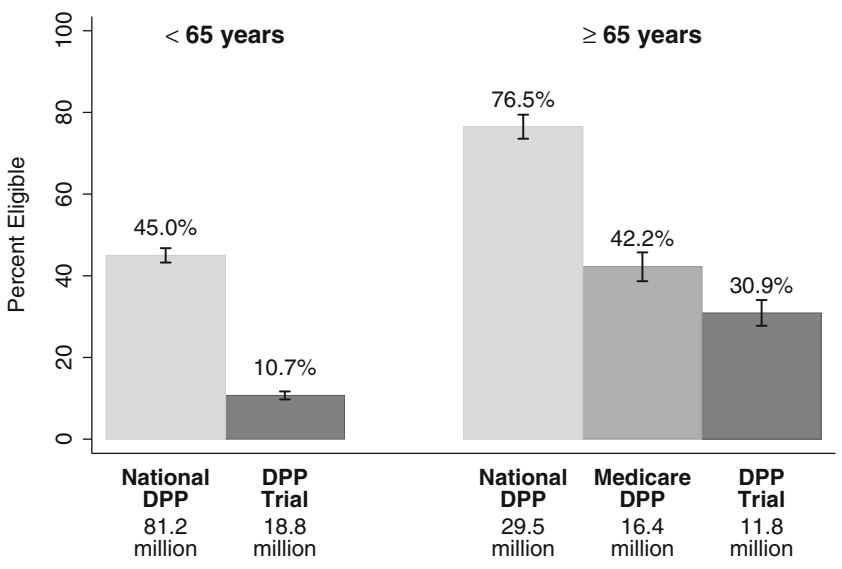

Fig. 1 Proportion and number of US adults aged $\geq 20$ years meeting eligibility criteria for Diabetes Prevention Programs, stratified by age $<65$ years and $\geq 65$ years, NHANES 2007-2016. Standardized to the 2016 US adult population using the American Community Survey. 
Table 1 Percent, Number, and Characteristics of US Adults by Diabetes Prevention Program Eligibility, Stratified by Age $<65$ Years and $\geq$ 65 Years, NHANES 2007-2016

\begin{tabular}{|c|c|c|c|c|c|}
\hline & \multicolumn{2}{|c|}{20 to $<65$ years } & \multicolumn{3}{|l|}{$\geq 65$ years } \\
\hline & \multirow{2}{*}{$\begin{array}{l}\begin{array}{l}\text { Eligible for } \\
\text { National DPP }\end{array} \\
n=3233\end{array}$} & \multirow{2}{*}{$\begin{array}{l}\begin{array}{l}\text { Eligible for } \\
\text { DPP Trial }\end{array} \\
n=887\end{array}$} & \multirow{2}{*}{$\begin{array}{l}\begin{array}{l}\text { Eligible for } \\
\text { National DPP }\end{array} \\
n=1289\end{array}$} & \multirow{2}{*}{$\begin{array}{l}\begin{array}{l}\text { Eligible for } \\
\text { Medicare DPP }\end{array} \\
n=828\end{array}$} & \multirow{2}{*}{$\begin{array}{l}\begin{array}{l}\text { Eligible for } \\
\text { DPP Trial }\end{array} \\
n=609\end{array}$} \\
\hline & & & & & \\
\hline Age (years) & $46.5(0.3)$ & $48.7(0.5)$ & $72.3(0.2)$ & $72.9(0.3)$ & $73.2(0.3)$ \\
\hline Female $(\%)$ & $47.4(1.0)$ & $46.8(2.3)$ & $55.1(1.5)$ & $56.3(1.7)$ & $52.5(2.4)$ \\
\hline \multicolumn{6}{|l|}{ Race $(\%)$} \\
\hline \multicolumn{6}{|l|}{ Non-Hispanic } \\
\hline White & $65.2(1.9)$ & $63.4(2.5)$ & $81.5(1.6)$ & $79.5(2.0)$ & $80.7(2.1)$ \\
\hline Black & $12.1(1.0)$ & $9.8(1.1)$ & $7.0(0.9)$ & $7.5(1.1)$ & $6.4(1.2)$ \\
\hline $\mathrm{Asian}^{\mathrm{a}}$ & $4.3(0.6)$ & $6.6(1.0)$ & $3.2(0.6)$ & $3.7(0.9)$ & $4.5(1.1)$ \\
\hline All Hispanic & $17.0(1.5)$ & $19.7(2.0)$ & $7.2(1.0)$ & $8.2(1.2)$ & $8.6(1.4)$ \\
\hline Mexican American & $10.8(1.2)$ & $13.1(1.5)$ & $3.7(0.7)$ & $4.5(0.9)$ & $4.9(1.0)$ \\
\hline \multicolumn{6}{|l|}{ Education $^{\mathrm{b}}(\%)$} \\
\hline More than high school & $59.2(1.5)$ & $56.0(2.3)$ & $54.0(2.1)$ & $48.1(2.6)$ & $46.8(2.9)$ \\
\hline High school & $23.4(1.1)$ & $23.2(1.8)$ & $25.9(1.6)$ & $29.7(1.9)$ & $29.3(2.2)$ \\
\hline Less than high school & $17.4(1.0)$ & $20.7(1.5)$ & $20.1(1.5)$ & $22.2(1.7)$ & 23.9 (1.9) \\
\hline Body mass index $\left(\mathrm{kg} / \mathrm{m}^{2}\right)$ & $32.6(0.2)$ & $33.2(0.3)$ & $30.7(0.2)$ & $31.2(0.3)$ & $31.2(0.3)$ \\
\hline Waist circumference $(\mathrm{cm})^{\mathrm{c}}$ & $107.5(0.3)$ & $109.8(0.7)$ & $106.5(0.4)$ & $107.6(0.5)$ & $108.3(0.6)$ \\
\hline $\operatorname{HbA} 1 \mathrm{c}(\%)$ & $5.4(0.01)$ & $5.8(0.04)$ & $5.6(0.02)$ & $5.7(0.02)$ & $5.8(0.03)$ \\
\hline Fasting glucose $(\mathrm{mg} / \mathrm{dL})$ & 103. $(0.4)$ & $116(1.0)$ & $104(0.6)$ & $110(0.8)$ & $114(0.9)$ \\
\hline 2-h glucose $(\mathrm{mg} / \mathrm{dL})$ & $128(1.1)$ & $190(2.4)$ & $146(1.9)$ & $172(2.2)$ & $193(2.3)$ \\
\hline Systolic blood pressure $(\mathrm{mmHg})^{\mathrm{d}}$ & $123(0.3)$ & $126(0.7)$ & $130(0.7)$ & $131(0.8)$ & $132(1.1)$ \\
\hline Diastolic blood pressure $(\mathrm{mmHg})^{\mathrm{d}}$ & $73(0.3)$ & $74(0.6)$ & $64(0.5)$ & $63(0.6)$ & $63(0.7)$ \\
\hline Total cholesterol $(\mathrm{mg} / \mathrm{dL})^{\mathrm{e}}$ & $202(1.0)$ & $203(2.0)$ & $197(1.6)$ & $197(1.9)$ & $194(2.0)$ \\
\hline LDL-cholesterol $(\mathrm{mg} / \mathrm{dL})^{\mathrm{f}}$ & $124(0.8)$ & $120(1.7)$ & $115(1.7)$ & $116(2.0)$ & $114(2.0)$ \\
\hline HDL-cholesterol $(\mathrm{mg} / \mathrm{dL})^{\mathrm{g}}$ & $50(0.4)$ & $47(0.7)$ & $57(0.8)$ & $54(0.7)$ & $53(0.7)$ \\
\hline Triglycerides $(\mathrm{mg} / \mathrm{dL})^{\mathrm{h}}$ & $150(3.1)$ & $183(9.1)$ & $133(3.1)$ & $142(3.6)$ & $144(3.6)$ \\
\hline History of cardiovascular disease $\mathrm{i}, \%$ & $4.1(0.4)$ & $5.3(0.9)$ & $19.8(1.3)$ & $21.2(1.6)$ & $22.5(2.0)$ \\
\hline $\begin{array}{l}\text { Prediabetes by fasting glucose } 100-125 \mathrm{mg} / \mathrm{dL} \text {, } \\
\text { HbA1c } 5.7-6.4 \% \text {, or } 2 \text {-h glucose } 140-199 \mathrm{mg} / \mathrm{dL} \\
(\%)\end{array}$ & $71.9(1.2)$ & $(100)$ & $73.1(1.7)$ & $(100)$ & $(100)$ \\
\hline History of gestational diabetes ${ }^{\mathrm{j}}(\%)$ & $9.9(1.1)$ & $12.5(2.0)$ & $1.0(0.6)$ & $1.2(0.8)$ & $1.7(1.2)$ \\
\hline Needs special equipment to walk (\%) & $5.3(0.5)$ & $7.6(1.1)$ & $15.1(1.3)$ & $15.4(1.6)$ & $15.6(2.0)$ \\
\hline
\end{tabular}

Mean (standard error) unless noted as \%. Columns are not mutually exclusive.Standardized to the 2016 US adult population using the American Community Survey

${ }^{a}$ Proportions are from the 2011-2016 NHANES survey years during which Asians were oversampled and sample sizes are sufficient for subgroup analysis

${ }^{b} 2$ individuals missing information on education

${ }^{c} 75$ individuals missing waist circumference measurements

${ }^{d} 130$ individuals do not have at least 2 systolic/diastolic blood pressure measurements

${ }^{e} 16$ individuals missing total cholesterol measurements

${ }^{f} 103$ individuals missing LDL measurements from 2007 to 2014; data not yet available for 2015-2016

${ }^{g} 16$ individuals missing $H D L$ measurements

${ }^{h} 15$ individuals missing measurements for triglycerides from 2007 to 2014; data not yet available for 2015-2016

${ }^{i} 21$ individuals missing information on history of cardiovascular disease, defined as self-report of stroke, coronary heart disease, heart attack/ myocardial infarction

${ }^{j}$ Females only

HbAlc, hemoglobin Alc, DPP, Diabetes Prevention Program

HbA1c, fasting glucose, and 2-h glucose (Table 1). Older adults eligible for National DPP but not Medicare DPP had a mean $\mathrm{HbA} 1 \mathrm{c}$ of $5.3 \%$ and fasting glucose of $95 \mathrm{mg} / \mathrm{dL}$ (33\% with prediabetes by ADA definition), whereas those eligible for Medicare DPP had a mean $\mathrm{HbA1c}$ of $5.7 \%$ and fasting glucose of $110 \mathrm{mg} / \mathrm{dL}$ (100\% with prediabetes).

\section{DISCUSSION}

Almost half of US adults met eligibility criteria for National or Medicare DPP. Adults eligible for these community-based programs represent very different populations - with more favorable cardiometabolic profiles - compared to the original participants of the DPP Trial. Our estimates provide useful information on the number of US adults eligible for these established programs but do not reflect program enrollment or account for eligibility restrictions such as life-limiting diseases or disability.

Older adults meeting National DPP but not Medicare DPP eligibility criteria were a lower-risk population, only $1 / 3$ of whom had prediabetes. While weight loss interventions have multiple benefits, including improving blood pressure, cholesterol, mobility, and quality of life, ${ }^{5}$ DPP participation by highrisk, young and middle-aged adults may pay the greatest dividends for reducing long-term diabetes complications in the USA. Creating sustainable community-based programs will be challenging; there is growing interest in digital platforms to deliver these interventions. ${ }^{6}$ Ensuring access to 
recognized DPPs for high-risk individuals while simultaneously pursuing population-based prevention policies will be critical for reducing the burden of diabetes in the USA.

Acknowledgements: The authors thank NHANES staff and participants.

Corresponding Author: Elizabeth Selvin, $\mathrm{PhD}, \mathrm{MPH}$; Department of Epidemiology and the Welch Center for Prevention, Epidemiology and Clinical Research Johns Hopkins Bloomberg School of Public Health, Baltimore, MD, USA (e-mail: eselvin@jhu.edu).

Author Contributions A.K. Lee and B. Warren conceived and designed the study. A.K. Lee and C. Liu conducted statistical analysis and drafted the manuscript. $B$. Warren contributed to the interpretation of data and drafting the manuscript. K. Foti and E. Selvin provided supervision and contributed to the interpretation of the data and the revision of the manuscript for critical intellectual content. All authors had final approval of the version submitted for publication. E. Selvin is the guarantor of this work.

Funding B. Warren, A.K. Lee, and K. Foti were supported by NIH/ NHLBI grant T32HL007024. E. Selvin was supported by NIH/NIDDK grant K24DK106414.

\section{Compliance with Ethical Standards:}

Conflict of Interest: The authors declare that they do not have a conflict of interest.
Role of the Funding Source: The funding source had no role in data analysis, drafting the manuscript, or the decision to submit the manuscript for publication.

Publisher's Note: Springer Nature remains neutral with regard to jurisdictional claims in published maps and institutional affiliations.

\section{REFERENCES}

1. Diabetes Prevention Program Research Group. Reduction in the Incidence of Type 2 Diabetes With Lifestyle Intervention or Metformin. N Engl J Med. 2002;346(6):393-403.

2. Centers for Disease Control and Prevention. Diabetes Prevention Recognition Program: Standards and Operating Procedures, March 1, 2018. Available at: https://www.cdc.gov/diabetes/prevention/pdf/dprp-standards.pdf. Accessed December 19, 2018.

3. Centers for Medicare and Medicaid Services. Medicare Diabetes Prevention Program (MDPP) Expanded Model. Available at: https://innovation.cms. gov/initiatives/medicare-diabetes-prevention-program/. Accessed December 19, 2018.

4. Department of Health and Human Services. Certification of Medicare Diabetes Prevention Program. Available at: https://www.cms.gov/Research-Statistics-Data-and-Systems/Research/ActuarialStudies/Downloads/Diabetes-Prevention-Certification-2016-03-14.pdf Accessed Oct 17, 2018.

5. Orchard TJ, Temprosa M, Barrett-Connor E, et al. Long-term effects of the Diabetes Prevention Program interventions on cardiovascular risk factors: A report from the DPP Outcomes Study. Diabet Med. 2013;30(1):46-55.

6. Joiner $\mathbf{K L}, \mathbf{N a m} \mathbf{S}$, Whittemore $\mathbf{R}$. Lifestyle interventions based on the diabetes prevention program delivered via eHealth: A systematic review and meta-analysis. Prev Med. 2017;100:194-207. 